\title{
Up-regulation of miR-130b expression level and down-regulation of miR-218 serve as potential biomarker in the early detection of human osteosarcoma
}

\author{
Afshin Taheriazam ${ }^{1}$, Amir Jouya Talaei ${ }^{2}$, Mohammad Jamshidi ${ }^{3,4}$, Mohammadreza Shakeri ${ }^{5}$, Samaneh Khoshbakht ${ }^{6}$,
} Emad Yahaghi ${ }^{7}$ and Marjan Shokrani ${ }^{8^{*}}$

\section{Abstract}

Background: Osteosarcoma (OS) is a primary malignant bone tumor with high morbidity that principally emerges in children and adolescents. MiRNAs regulate a variety of normal physiologic processes and are involved in tumorigenesis and development of multiple malignancies, including OS. This study was aimed to evaluate the clinical significance of miR-130b and miR-218 in osteosarcoma patient.

Methods: We utilized quantitative real-time PCR to evaluate the level of miR-130b and miR-218 expressions in OS patients and normal tissues and their relationship with clinicopathological features and survival in OS patients.

Results: QRT-PCR indicated that miR-130b expression in tumor tissues was strongly elevated than adjacent non-tumor tissues $(P<0.001)$, while the level of miR-218 expressionin osteosarcoma tissues was down-regulated than adjacent non-tumor tissues $(P<0.001)$. We evaluated the cinical significance of miR-130b and miR-218 in osteosarcoma. Clinical correlation analysis showed that increased expression of miR-130b and decreased expression of miR-218 were significantly associated with advanced tumor stage $\left(x^{2}=6.285, P<0.009 ; x^{2}=7.172, P<0.007\right)$, distant metastasis $\left(x^{2}=5.528 ; P<0.001 ; x^{2}=4.617, P<0\right.$.001) and size of tumor $\left(x^{2}=5.01, P=0.013 ; x^{2}=4.271, P=0.019\right)$.

Conclusions: Taken together, our data indicated that high miR-130b level and low level of miR-218 are associated with poor clinicopathological characteristics. Furthermore, miR-130b may play a key role in the progression of osteosarcoma.

Keywords: Mir-130b/218, Osteosarcoma, Regulation, Patient, Diagnosis

\section{Background}

Osteosarcoma (OS) is a primary malignant bone tumor with high morbidity in children and young adults; hat is more common in males than in females [1-4]. Despite current treatments combining chemotherapy, surgery, the 5-year cumulative survival rate of primary osteosarcoma was only $50 \%-60 \%[5,6]$. Therefore, the discovery of new biomarkers for the diagnosis, prognosis, and treatment of OS remains an important but unmet clinical need. miRNAs are a family of small, non-coding,

\footnotetext{
* Correspondence: drshokrani.tums@gmail.com

${ }^{8}$ Graduate, Faculty of Medicine, Tehran University of Medical Sciences, Tehran, Iran

Full list of author information is available at the end of the article
}

endogenous RNAs, that inhibit gene expression by binding to the 3'untranslated region ( $3^{\prime}$-UTR) of mRNA sequence, leading to translational degradation or repression $[7,8]$. Studies have also shown that miRNAs are involved in tumor genesis and cancer progression. MiRNAs can function as either tumor suppressors or oncogenes according to their target genes $[9,10]$. Many miRNAs are deregulated in various cancer subtypes [11-14].

MiRNAs have been indicated to be correlated with the proliferation, differentiation, apoptosis and invasion of tumor cells [15]. However, the role of miRNAs in osteosarcoma development has only recently been investigated and further investigations are needed to clarify the role miRNAS in terms of osteosarcoma. MiR-130b has been 
studied in various types of human cancers [16-20]. Down-regulation of miR-130b has been reported in endometrial cancer, pituitary adenomas, papillary thyroid carcinoma, and pancreatic cancer [18-21]. Nevertheless, it has been shown that miR-130b expression was aberrantly increased in melanoma, colorectal cancer, bladder cancer, and gastric carcinoma $[16,17,22-24]$.

MiR-218 has been reported to be significantly deregulated in many kinds of tumors [25-30]. It was downregulated in lung, prostate, cervical, colon, gastric, bladder cancer and hepatocellular carcinoma [25-29]. Moreover, decreased expression of miR-218 was related to a significant worse survival of HCC patients. Down regulation of miR-218 was found in osteosarcoma tissues [31]. Moreover, it has been reported that miR-218 inhibited osteosarcoma cell migration and invasion by downregulating T-cell lymphoma invasion and metastasis 1 (TIAM1), matrix metalloproteinase2 (MMP2) and MMP9 [31]. However, it is important to evaluate the clinical significance of miR-130b and miR-218 in osteosarcoma patients.

\section{Materials and methods}

Ethical approval for the study was obtained according to the Declaration of Helsinki. All subjects were volunteers and informed consents were obtained.

\section{Patients and tissue specimens}

Cancerous tissues and adjacent non-tumor tissues ( $>3 \mathrm{~cm}$ distance to the resection margin) were obtained from 30 patients who underwent curative resection of osteosarcoma between December 2007 and September 2013 in Mashhad and Tabriz hospitals, Iran. All clinical samples were used affer obtaining informed consent. Moreover, histological subtype and tumor grade were determined using the World Health Organization (W/HO) criteria (Fig. 1). The tissues were stored at $-80{ }^{\circ} \mathrm{C}$ until use. Union for International Cancer Control (UICC) tumor-nodemetastases (TNM) Staging Classification was used for the staging of the tumor. The clinical features of all enrolled patients were shown in Table 1.

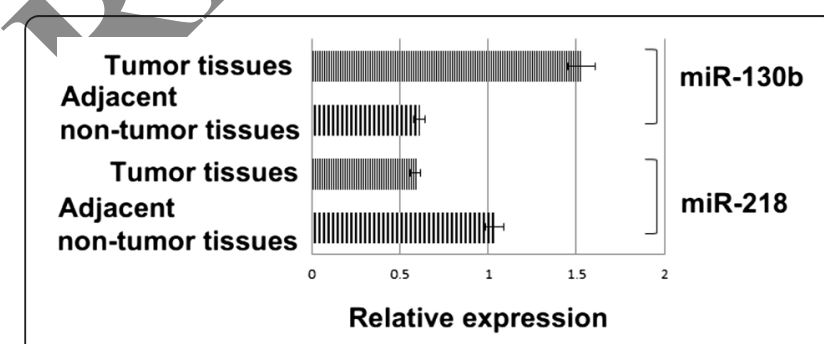

Fig. 1 Expression levels of miR-130b and miR-218 in osteosarcoma tissues and adjacent non-tumor tissues

\section{RNA extraction and qRT-PCR}

Briefly, total RNA was extracted from the tissues using TRIzol reagent (Invitrogen, Carlsbad, CA, USA), according to the manufacturer's instructions. Two microliters of cDNA obtained from each sample was amplified and quantified by real-time PCR of TaqMan Human MiRNA Assay (Applied Biosystems) according to the manufacturer's protocol. MiRNAs expressions relative to U6 were evaluated using the comparative eycle threshold (CT) method.

\section{Statistical analysis}

The GraphPad Prism 5 software (GraphPad/Software, Inc., San Diego, CA, USA) was applied for chi-square test and Two-tailed Student's $t$ test. Differences were considered statistically significant when $p$ was less than 0.05 .

\section{Results and Discussion}

QRT-PCR indicated that miR-130b expression in tumor tissues was strongly elevated than adjacent non-tumor tissues ( $1.04 \pm 0.31$ vs. $0.59 \pm 0.12, P<0.001$; Fig. 2$)$, while the level of niR 218 expression in osteosarcoma tissues was down-regulated than adjacent non-tumor tissues ( $0.61 \pm 0.21$ vs. $1.53 \pm 0.42, P<0.001$; Fig. 2 ).

We evaluated the clinical significance of miR-130b and miR-218 in osteosarcoma. Clinical correlation analysis showed that increased expression of miR$130 \mathrm{~b}$ and decreased expression of miR-218 were significantly associated with advanced tumor stage $\left(x^{2}=\right.$ 6.285, $\left.P<0.007 ; x^{2}=7.172, P<0.009\right)$, distant metastasis $\left(x^{2}=5.528 ; P<0.001 ; x^{2}=4.617, P<0.001\right)$ and size of tumor $\left(x^{2}=5.01, P=0.013 ; x^{2}=4.271, P=0.019\right)$, (Table 1).

These results suggested that high miR-130b level and low level of miR-218 are associated with poor clinicopathological characteristics.

There is growing evidence that miRNAs can act as either oncogenes or tumor suppressor, depending on their target genes. Dysregulation of miRNAs has been linked to different malignancies [32, 33]. It has been already reported that different kinds of miRNAs are up-regulated or underexpressed in OS tissues and cell lines. These miRNAs are involved in occurrence and development of many kinds of tumors [34]. Down-regulation of miR130b has been documented in endometrial cancer, pituitary adenomas, papillary thyroid carcinoma, and pancreatic cancer [18-21]. On the other hand, it was shown that miR-130b expression was increased in melanoma, colorectal cancer, bladder cancer, and gastric carcinoma $[16,17,22-24]$. Our findings indicated that miR-130b expression was strongly elevated in tumor tissues when compared with adjacent non-tumor tissues. Clinical correlation analysis showed that increased expression of miR-130b was significantly associated with advanced 
Table 1 Association between the clinicopathological parameters and expression of miRNAs in the osteosarcoma patients

\begin{tabular}{|c|c|c|c|c|c|c|c|}
\hline \multirow[t]{2}{*}{ Clinicopathological features } & \multirow[t]{2}{*}{ No. of cases } & \multicolumn{2}{|c|}{ Expression of miR-130b } & \multicolumn{2}{|c|}{ Expression of miR-218 } & \multirow[t]{2}{*}{$P$ value of miR-130b } & \multirow[t]{2}{*}{$P$ value of miR-218 } \\
\hline & & Low $=11$ & High $=19$ & Low $=17$ & High $=13$ & & \\
\hline Gender & & & & & & 0.741 & 0.712 \\
\hline Male & 17 & 7 & 10 & 11 & 6 & & \\
\hline Female & 13 & 4 & 9 & 6 & 7 & & \\
\hline Age & & & & & & 0.517 & \\
\hline$<24$ & 12 & 4 & 8 & 7 & 5 & & \\
\hline$\geq 25$ & 18 & 7 & 11 & 10 & 8 & & \\
\hline Tumor diameter (cm) & & & & & & 0.013 & \\
\hline$\leq 6$ & 16 & 9 & 7 & 6 & 10 & & \\
\hline$>6$ & 14 & 2 & 12 & 11 & 3 & & \\
\hline Histology & & & & & & & 0.503 \\
\hline Conventional osteosarcoma & 20 & 6 & 14 & 11 & 9 & & \\
\hline Others & 10 & 5 & 5 & 6 & 4 & & \\
\hline Clinical stage & & & & & & & 0.007 \\
\hline । & 12 & 8 & 4 & 4 & 8 & & \\
\hline$\|$ & 10 & 3 & 7 & 6 & & & \\
\hline III & 8 & 0 & 8 & 7 & & & \\
\hline Distant metastasis & & & & & & $<0.001$ & $<0.001$ \\
\hline No & 18 & 8 & 10 & & 11 & & \\
\hline Yes & 12 & 3 & 9 & & 2 & & \\
\hline
\end{tabular}

tumor stage, distant metastasis and size of tumon. These results suggested that high miR-130b level is associated with poor clinicopathological characteristics. Elevated expression level of miR-130b was associated with poorer prognosis of osteosarcoma patients. A previous study indicated that in CRC miR-130b induces EMT through a pathway that appears to be independent of DICER1 and its downstream target miR-200c. Moreover, the PPAR $\gamma$ is as a direct functional target of miR-130b in colorectal cancer. PPAR $\gamma$ is a CRC-independent prognostic factor implicated in cell differentiation and suppression of cell growth likely through up-regulation of its target genes E-cadherin, p21, and PTEN in colorectal cancer [17]. It has been found that, miR-130b could contribute to EMT

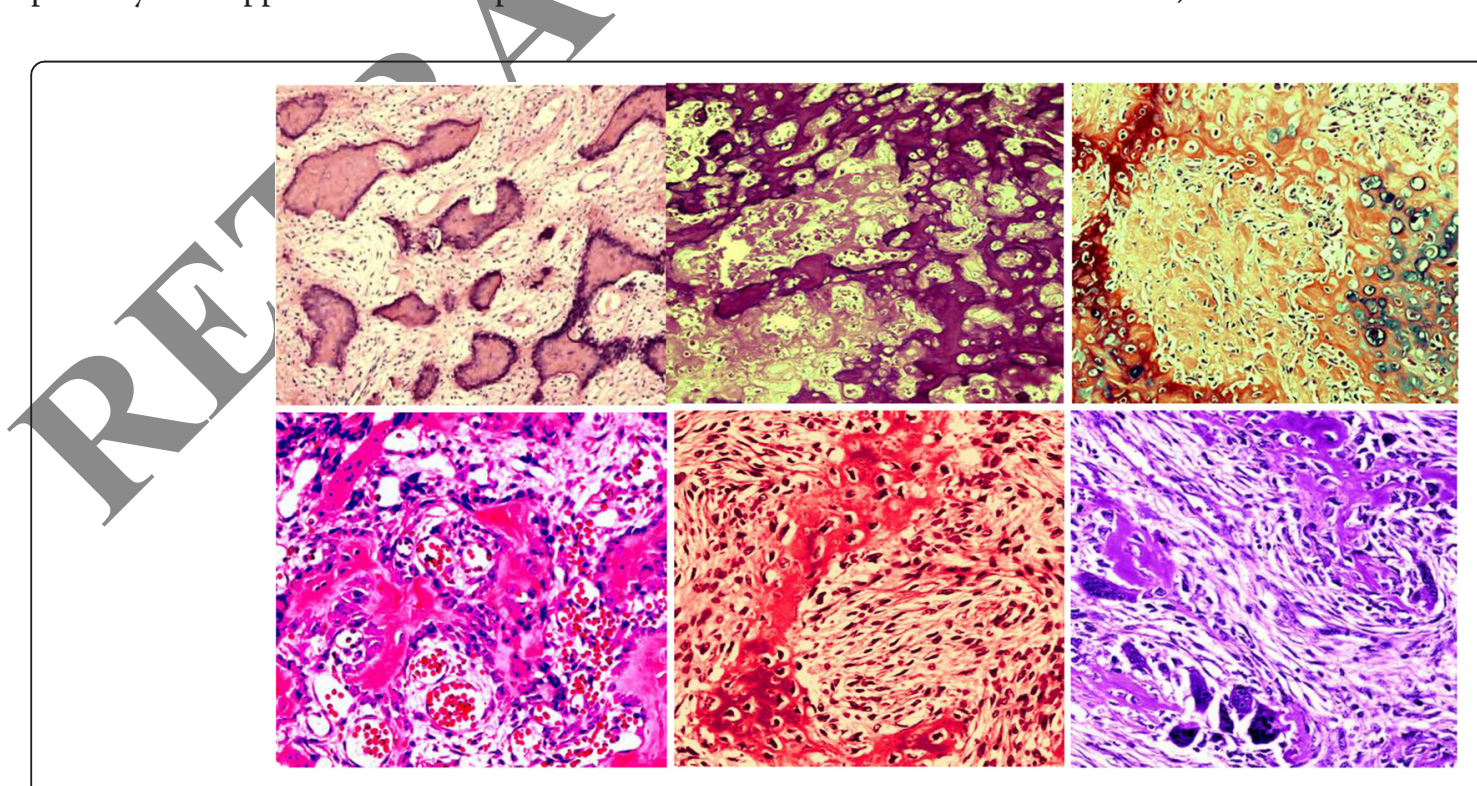

Fig. 2 Pathology of osteosarcomas. High-powered photomicrographs of human osteosarcomas show condensation of the neoplastic cells (H\&E) 
of cancer cells by targeting DICER1 [35]. The involvement of miR-130b in CRC-related angiogenesis and EMT has been previously shown. In hypoxic conditions, miR-130b represses DDX6 leading to increased activity of HIF1 $\alpha$, a well-known VEGF inducer.

Furthermore, deregulation of miR-218 was reported in many kinds of tumors [25-30]. Down-regulation of it has been found in lung, prostate, cervical, colon, gastric, bladder cancer and hepatocellular carcinoma [25-29]. Moreover, decreased expression of miR-218 was related to a significant worse survival of HCC patients. Down regulation of miR-218 was found in osteosarcoma tissues [31]. Moreover, it has been reported that miR-218 inhibited osteosarcoma cell migration and invasion by downregulating T-cell lymphoma invasion and metastasis 1 (TIAM1), matrix metalloproteinase2 (MMP2) and MMP9 [31]. In the present study, the level of miR-218 expression in osteosarcoma tissues was down-regulated in comparison with adjacent non-tumor tissues. We evaluated the clinical significance of miR-218 in osteosarcoma. Clinical correlation analysis showed that decreased expression of miR-218 was significantly associated with advanced tumor stage, distant metastasis and size of tumor. These results suggested that low level of miR-218 is associated with poor clinicopathological characteristics.

It has been reported that the low level of miR-218 is associated with TNM stage, lymph node metastasis and histological differentiation in colon cancer. Moreover, patients with low miR-218 expression had shorter survival in colon cancer [27]. Lower level of miR-218 has been found in patients with large tumor size and advanced TNM tumor stage in hepatocellular carcinoma tissues [30]. Our findings suggested that that miR-218 may be a potential marker in osteosarcoma patients. A previous study indicated that LEF1 is a new direct target of miR-218, and miR-218 can reduce protein levels of LEF1 and MMP-9 in glioblastoma cells. They hypothesized that miR-218 can directly target LEF1, resulting in reduced synthesis of MMP-9. Moreover, they concluded that miR-218 is involved in the invasive behavior of GBM cells and by targeting LEF1 and blocking the invasive axis, miR-218-LEF1-MMPs, it may be useful for developing potential clinical strategies [36]. Jin et al. [31] indicated that miR-218 can act as inhibitor of osteosarcoma cell migration and invasion by down-regulating TIAM1, MMP2 and MMP9 expression [18]. However, further studies are needed to clarify the role of miR-218 in osteosarcoma cell proliferation and apoptosis.

\section{Conclusions}

In summary, our data indicated that high miR-130b level and low level of miR-218 are associated with poor clinicopathological characteristics. Furthermore, miR-130b may play a key role in the progression of osteosarcoma.

\section{Abbreviations}

OS: Osteosarcoma; 3'-UTR: 3'untranslated region; CT: Cycle threshold; UICC: Union for International Cancer Control; WHO: World Health Organization; TNM: Tumor-nodemetastases; TIAM1: T-cell lymphoma invasion and metastasis1; MMP2: Matrix metalloproteinase2.

\section{Competing interests}

The authors declare that they have no competing interests.

\section{Authors' contributions}

AT, AJT, MJ, MSH, SKH and EY participated in sample collection and proce and coordination and helped to draft the manuscript and manuscript preparation. MSH participated in design of thestudy and wes and The authors read and approved the final manuscript.

Acknowledgements
We gratefully thank Dr. Javanbakht in providing the diagnosis of bone neoplasms with histological interpretation and for his editorial and administrative assistance and his scientific review in the preparation of this article.

\section{Author details}

'Department of Orthopedics Surgery, Tehrăn Medical Sciences Branch, Islamic Azad University, Tehran, Iran. ${ }^{2}$ Department of Genetics, Faculty of Life Sciences, Azad University of Tehran Medical Sciences Branch, Tehran, Iran. ${ }^{3}$ Cellular and Molecular Research Center, Zahedan University of Medical Sciences, Zahedan, Iran. ${ }^{4}$ Department of Clinical Biochemistry, School of Medicine, Zahedan University of Medical Sciences, Zahedan, Iran.

${ }^{5}$ Department of Orthopaedic and Trauma Surgery, Birjand University of Medical Sciences, Birjand, Iran. ${ }^{6}$ Department of Statistics, Faculty of Sciences, Islamic Azad University, Mashhad Branch, Mashhad, Iran. ${ }^{7}$ Department of Molecular Biology, Baqiyatallah University of Medical Sciences, Tehran, Iran. ${ }^{8}$ Graduate, Faculty of Medicine, Tehran University of Medical Sciences,
Tehran, Iran.

Received: 11 August 2015 Accepted: 1 October 2015

Published online: 07 October 2015

\section{References}

1. Tang J, Shen L, Yang Q, Zhang C. Overexpression of metadherin mediates metastasis of osteosarcoma by regulating epithelial-mesenchymal transition. Cell Prolif. 2014;47(5):427-34.

2. Montanaro L, Mazzini G, Barbieri S, Vici M, Nardi-Pantoli A, Govoni M. Different effects of ribosome biogenesis inhibition on cell proliferation in retinoblastoma protein- and p53-deficient and proficient human osteosarcoma cell lines. Cell Prolif. 2007:40(4):532-49.

3. Botter SM, Neri D, Fuchs B. Recent advances in osteosarcoma. Curr Opin Pharmacol. 2014;16C:15-23.

4. Gill J, Ahluwalia MK, Geller D, Gorlick R. New targets and approaches in osteosarcoma. Pharmacol Ther. 2013;137:89-99.

5. Thayanithy V, Park C, Sarver AL, Kartha RV, Korpela DM, Graef AJ. Combinatorial treatment of DNA and chromatin-modifying drugs cause cell death in human and canine osteosarcoma cell lines. PLoS One. 2012;7(9):e43720.

6. Hu H, Zhang Y, Cai XH, Huang JF, Cai L. Changes in microRNA expression in the MG-63 osteosarcoma cell line compared with osteoblasts. Oncol Lett. 2012;4(5):1037-42.

7. Li Z, Yu X, Shen J, Wu WK, Chan MT. MicroRNA expression and its clinical implications in Ewing's sarcoma. Cell Prolif. 2015;48(1):1-6.

8. Yu X, Li Z. MicroRNAs regulate vascular smooth muscle cell functions in atherosclerosis (review). Int J Mol Med. 2014;34(4):923-33.

9. Hirata H, Ueno K, Shahryari V, Tanaka Y, Tabatabai ZL, Hinoda Y. Oncogenic miRNA-182-5p targets Smad4 and RECK in human bladder cancer. PLoS One. 2012;7(11):e51056.

10. Liu G, Jiang C, Li D, Wang R, Wang W. MiRNA-34a inhibits EGFR-signalingdependent MMP7 activation in gastric cancer. Tumour Biol. 2014;35(10):9801-6.

11. Shah NR, Chen H. MicroRNAs in pathogenesis of breast cancer: Implications in diagnosis and treatment. World J Clin Oncol. 2014;5:48-60.

12. Drusco A, Nuovo GJ, Zanesi N, Di Leva G, Pichiorri F, Volinia S, et al. MicroRNA profiles discriminate among colon cancer metastasis. PLoS One. 2014;9:e96670 
13. D’Anzeo M, Faloppi L, Scartozzi M, Giampieri R, Bianconi M, Del Prete M, et al. The role of micro-RNAs in hepatocellular carcinoma: from molecular biology to treatment. Molecules. 2014;19:6393-406

14. Kang SM, Lee HJ. MicroRNAs in human lung cancer. Exp Biol Med (Maywood). 2014;239(11):1505-13.

15. Chang SJ, Weng SL, Hsieh JY, Wang TY, Chang MD, Wang HW. MicroRNA34a modulates genes involved in cellular motility and oxidative phosphorylation in neural precursors derived from human umbilical cord mesenchymal stem cells. BMC Med Genet. 2011;4:65.

16. Lai KW, Koh KX, Loh M, Tada K, Subramaniam MM. MicroRNA-130b regulates the tumour suppressor RUNX3 in gastric cancer. Eur J Cancer. 2010;46(8):1456-63.

17. Colangelo T, Fucci A, Votino C, Sabatino L, Pancione M. MicroRNA-130b promotes tumor development and is associated with poor prognosis in colorectal cancer. Neoplasia. 2013;15(10):1218-31.

18. Dong P, Karaayvaz M, Jia N, Kaneuchi M, Hamada J, Watari H. Mutant p53 gain-of-function induces epithelial-mesenchymal transition through modulation of the miR-130b-ZEB1 axis. Oncogene. 2013;32(27):3286-95.

19. Leone V, Langella C, D'Angelo D, Mussnich P, Wierinckx A, Terracciano L. Mir-23b and miR-130b expression is downregulated in pituitary adenoma. Mol Cellular Endocrinol. 2014;390(1-2):1-7.

20. Zhao G, Zhang JG, Shi Y, Qin Q, Liu Y, Wang B. MiR-130b is a prognostic marker and inhibits cell proliferation and invasion in pancreatic cancer through targeting STAT. PLOS One. 2013;8(9):e73803.

21. Yip L, Kelly L, Shuai Y, Armstrong MJ, Nikiforov YE, Carty SE. MicroRNA signature distinguishes the degree of aggressiveness of papillary thyroid carcinoma. Ann Surg Oncol. 2011;18(7):2035-41.

22. Sand M, Skrygan M, Sand D, Georgas D, Gambichler T, Hahn SA. Comparative microarray analysis of microRNA expression profiles in primary cutaneous malignant melanoma, cutaneous malignant melanoma metastases, and benign melanocytic nevi. Cell Tissue Res. 2013;351(1):85-98.

23. Kim BH, Hong SW, Kim A, Choi SH, Yoon SO. Prognostic implications for high expression of oncogenic microRNAs in advanced gastric carcinoma J Surg Oncol. 2013;107(5):505-10.

24. Scheffer AR, Holdenrieder S, Kristiansen G, von Ruecker A, Muller SC, Ellinger J. Circulating microRNAs in serum: novel biomarkers for patients $W$ bladder cancer? World J Urol. 2014;32(2):353-8.

25. Xin SY, Feng XS, Zhou LQ, Sun JJ, Gao XL, Yao GL. Redud circulating microRNA-218 in gastric cancer and correlation with tumor invasion and prognosis. World J Gastroenterol. 2014,20(22):6906-11.

26. Davidson MR, Larsen JE, Yang IA, Hayward NK, Clarke BE, Duhig EE. MicroRNA218 is deleted and downregulated in lung squamous cell carcinoma. PLoS One. 2010;5(9):e12560.

27. He X, Dong Y, Wu CW, Zhao Z, Ng SS, Chan FK. MicroRNA-218 inhibits cell cycle progression and promotes apoptosis in colon cancer by downregulating BMI1 polycomb ring finger oncogene. Mol Med. 2013;18:1491-8.

28. Nishikawa R, Goto Y, Sakamoto S, Chiyomaru T, Enokida H, Kojima S Tumor-suppressive microRNA-218 inhibits cancer cell migration and invasion via targeting of LASP 1 in prostate cancer. Cancer Sci. 2014;105(7):802-1

29. Tatarano S, Chiyomaru T, Kawakami K, Enokida H, Yoshino H, Hidaka H. MiR-218 on the genomic loss region of chromosome 4 p15.31 functions as a tumor suppressor in bladder/cancer. Int J Oncol. 2011;39(1):13-21.

30. Tu K, Li C, Zheng X, YangW, Yao Y, Liu Q. Prognostic significance of miR-218 in human hepatocellular carcinoma and its role in cell growth. Oncol Rep. 2014;32(4):1571-7.

in J, Cai L, Liu ZM, Zhou XS. MiRNA-218 inhibits osteosarcoma cell migration and invasion by down-regulating of TIAM1, MMP2 and MMP9. Asian Pac J Cancer Prev. 2013;14(6):3681-4.

32. Bottai G, Pasculli B, Calin GA, Santarpia L. Targeting the microRNAregulating DNA damage/repair pathways in cancer. Expert Opin Biol Ther. 2014;14(11):1667-83.

33. Adams BD, Kasinski AL, Slack FJ. Aberrant regulation and function of MicroRNAs in cancer. Curr Biol. 2014;24:R762-76.

34. Nugent M. MicroRNA function and dysregulation in bone tumors: the evidence to date. Cancer Manag Res. 2014:6:15-25
35. Li BL, Lu C, Lu W, Yang TT, Qu J, Hong X. MiR-130b is an EMT-related microRNA that targets DICER1 for aggression in endometrial cancer. Med Oncol. 2013;30(1):484.

36. Liu Y, Yan W, Zhang W, Chen L, You G, Bao Z. MiR- 218 reverses high invasiveness of glioblastoma cells by targeting the oncogenic transcription factor LEF1. Oncol Rep. 2012;28(3):1013-21.

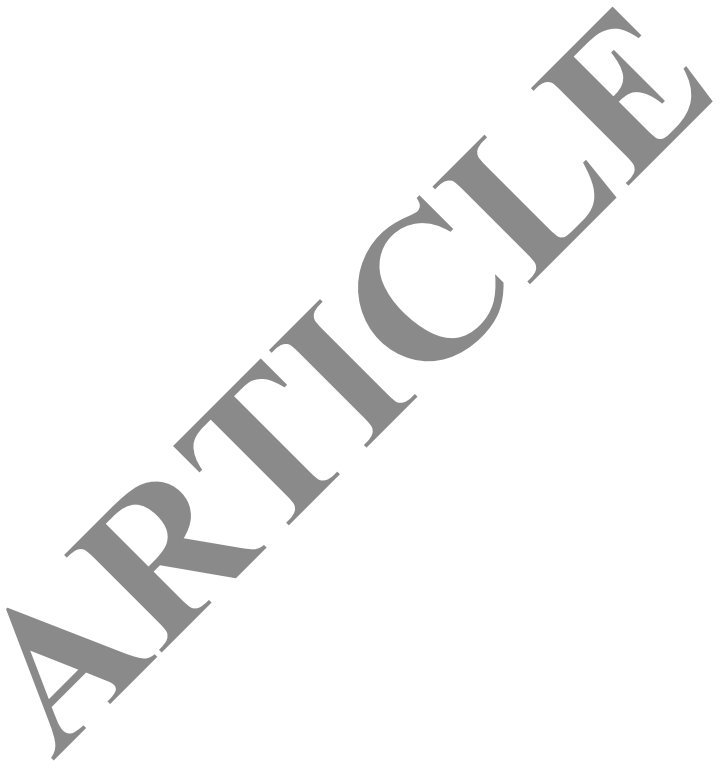

\section{Submit your next manuscript to BioMed Central and take full advantage of:}

- Convenient online submission

- Thorough peer review

- No space constraints or color figure charges

- Immediate publication on acceptance

- Inclusion in PubMed, CAS, Scopus and Google Scholar

- Research which is freely available for redistribution

Submit your manuscript at www.biomedcentral.com/submit
C Biomed Central 